\title{
Electrocardiographic nature of restored sinus rhythm after Cox maze procedure in patients with chronic atrial fibrillation who also had other cardiac surgery
}

Junya Kamata, Kenji Nakai, Naoki Chiba, Shunichi Hosokawa, Yoshihiro Sato, Masataka Nasu, Tatsuya Sasaki, Hiroto Kitahara, Hiroshi Izumoto, Yoko Yagi, Chuichi Itoh, Katsuhiko Hiramori, Kohei Kawazoe

\begin{abstract}
Objective-To characterise heart rate variability and high frequency components of restored sinus rhythm after the maze procedure. The maze procedure for chronic atrial fibrillation may prevent thrombotic events and improve the quality of life. However, the electrocardiographic nature of restored sinus rhythm after the maze procedure has not been fully elucidated.
\end{abstract}

Patients and methods-Between March 1993 and August 1995, 104 consecutive patients undergoing the maze procedure in combination with other cardiac surgery were studied. There were 100 long-term survivors (78 with mitral valve disease, 9 with aortic valve disease, 8 with congenital heart disease, and 5 others). Twenty age-matched patients with mitral valve disease who were in normal sinus rhythm preoperatively were enrolled as a control group. 30 days after surgery, the presence of arrhythmias and the circadian changes of heart rate variability were estimated by ambulatory electrocardiographic monitoring and the filtered $\mathbf{P}$ duration was evaluated by signal-averaged electrocardiogram.

Results-Restoration of sinus rhythm was observed in 73 of 100 cases. Subjects were classified into three groups according to their postoperative ambulatory electrocardiographic monitoring findings: patients in group $1(n=73)$ (1a: 58 regular sinus rhythm; 1b: 15 sinus rhythm with frequent premature atrial contractions (> 1000/day)); patients in group $2(n=$ 21) still had persistent atrial fibrillation; and patients in group $3(n=6)$ required permanent pacemaker implantation because of sick sinus syndrome. The success rate of restoration of sinus rhythm was $88 \cdot 3 \%$ if left atrial diameter was small (<65 mm). Circadian changes in the low frequency to high frequency power ratio in group 1 a were significantly diminished compared with control group $(P<0 \cdot 01)$. Furthermore, the filtered $P$ durations in group 1a (150 (20) $\mathrm{ms})$ and group $1 \mathrm{~b}(158$ (23) $\mathrm{ms}$ ) were longer than in the control group (122 (11) ms) $(P<0.01)$.

Conclusions-The maze procedure may result in a decreased sinus response and non-uniform transmission of impulses in the atrium.

(Heart 1997;77:50-55)

Keywords: chronic atrial fibrillation; valvar heart disease; heart rate variability; signal-averaged $P$ wave

Atrial fibrillation is a common but not a fatal arrhythmia. Cox et al identified three detrimental consequences of atrial fibrillation: symptomatic tachycardia, impaired haemodynamic function, and thromboembolic risk. ${ }^{1}$

The maze procedure is a radical surgical treatment for atrial fibrillation developed by Cox et al in 1991.1-5 It involves incision and resuturing of the atrium in the form of a maze. Cox et al suggested that atrial fibrillation was caused by multiple macro-reentries in the atrium (electrical excitation with large recurring cycles) and that these macro-reentries were prevented by the maze-like incisions. Detailed mapping studies conducted with multiple electrodes during atrial fibrillation indicated the presence of macro-reentries of various sizes, directions, and locations. ${ }^{6}$ With the maze procedure, a route of conduction of sinus node excitation to the atrioventricular node is assured. The incision is made so that multiple blind routes are given off from this route, and the atrium as a whole shows coordinated contraction.

Initially, the maze procedure was used as an isolated cardiac procedure in patients with chronic atrial fibrillation. ${ }^{3}$ However, with experience, this procedure came to be performed concomitantly with other cardiac procedures. ${ }^{7-11}$ Cardiac surgery for the underlying lesions alone does not usually abolish atrial fibrillation. ${ }^{12}$ Symptomatic tachycardia remains and the risk of thromboembolism is increased. In 1996, Kobayashi et al reported that the maze procedure can be combined with other cardiac surgery: they achieved rhythm conversion in $75.0 \%$ of their 200 patients. ${ }^{11}$ However, there were sporadic cases of postoperative bradyarrhythmia, such as sinus node dysfunction and intra-atrial block, and atrial tachyarrhythmia.

We used ambulatory electrocardiographic monitoring and signal-averaged electrocardiography to study the clinical characteristics and electrocardiographic nature of restored sinus 
rhythm after the maze procedure in patients with chronic atrial fibrillation who had concomitant surgical treatment of other heart disease.

\section{Patients and methods PATIENTS}

Between March 1993 and August 1995 we treated 104 consecutive patients with the maze procedure combined with other cardiac surgery. The study includes 100 long-term survivors. The group comprised 45 men and 55 women, with ages ranging from 21 to 77 years (mean 59.7 (9.9) years. Duration of atrial fibrillation before surgery (median (interquartile range)) was $9 \cdot 8(4 \cdot 2-14 \cdot 8)$ years. All patients had organic heart disease (78 mitral valve disease, nine aortic valve disease, eight congenital heart disease, and five other). Eight patients had had previous cardiac surgery $(8 \cdot 0 \%)$. The operations performed in conjunction with the maze procedure are shown in table 1.

Twenty age-matched patients with mitral valve disease who were in normal sinus rhythm preoperatively (11 men and nine women, with ages ranging from 39 to 75 years, mean $56 \cdot 3$ (7.9) years) were enrolled as a control group to eliminate the effect of the heart surgery for the underlying lesions. All control patients had heart surgery.

This study was approved by Iwate Medical University Hospital Ethics Committee, and informed consent was obtained from all subjects.

\section{MAZE PROCEDURE}

The operative procedure was fundamentally the same as that initially described by Cox, ${ }^{4}$ and basic atriotomies and cryoablation areas were similar to Cox's second modification of his original procedure. ${ }^{13}$

\section{ECHOCARDIOGRAPHY}

Echocardiographic examination was performed in all patients with a cardiac ultrasound imaging system (77035A, Hewlett Packard, Massachusetts, USA). Left atrial diameter and left ventricular ejection fraction were measured in a standard manner by a $M$ mode tracing taken from two dimensional parasternal long-axis views before surgery.

Table 1 Operations in conjunction with the maze procedure: comparison of the three groups (numbers)

\begin{tabular}{|c|c|c|c|c|}
\hline \multirow[b]{2}{*}{ Operation } & \multicolumn{2}{|l|}{ Group 1} & \multirow{2}{*}{$\begin{array}{l}\text { Group 2 } \\
(n=21)\end{array}$} & \multirow{2}{*}{$\begin{array}{l}\text { Group } 3 \\
(n=6)\end{array}$} \\
\hline & $1 a(n=58)$ & $1 b(n=15)$ & & \\
\hline Mitral valve repair & 17 & 5 & 10 & 3 \\
\hline OMC & 8 & 2 & 3 & 0 \\
\hline MVR & 15 & 6 & 6 & 3 \\
\hline Aortic valve repair & 1 & 0 & 0 & 0 \\
\hline AVR & 6 & 2 & 0 & 0 \\
\hline ASD closure & 4 & 0 & 2 & 0 \\
\hline VSD closure & i & 0 & 0 & 0 \\
\hline PDA division & i & 0 & 0 & 0 \\
\hline CABG & 2 & 0 & 0 & 0 \\
\hline Myxoma resection & 1 & 0 & 0 & 0 \\
\hline Valsalva closure & 1 & 0 & 0 & 0 \\
\hline Pericardiectomy & 1 & 0 & 0 & 0 \\
\hline
\end{tabular}

OMC, open mitral commissurotomy; MVR, mitral valve replacement; AVR, aortic valve replacement; ASD, atrial septal defect; VSD, ventricular septal defect; PDA, patent ductus arteriosus; CABG, coronary artery bypass grafting; Valsalva closure, closure of ruptured sinus of Valsalva.

\section{AMBULATORY ELECTROCARDIOGRAPHIC} MONITORING

A mean of 30 days after surgery, the presence of arrhythmias, the circadian variation in heart rate, and the circadian changes in the power spectrum of heart rate variability were estimated by ambulatory electrocardiographic monitoring (SCM-280, Fukuda Denshi, Tokyo, Japan). The percentage circadian variation in heart rate was defined with the following formula: ((maximum heart rate - minimum heart rate $) /$ mean heart rate $) \times 10^{2}(\%)$. After analysis of the ambulatory electrocardiographic monitoring, the $R R$ interval changes were transmitted to a personal computer (PC$9801 \mathrm{Vm}, \mathrm{NEC}$, Tokyo, Japan) and the time and frequency domain analysis of heart rate variability was performed in patients in group 1a. The following time domain heart rate variability indices were analysed: (1) mean $R R$ (mean of all coupling intervals between normal sinus beats), (2) SD (standard deviation of successive RR intervals), and (3) CV (coefficient of variation). The power spectrum density was calculated for $R R$ intervals by fast Fourier transform as follows: $R R$ intervals were sampled over a total of 1024 stable heart beats with no arrhythmias or artifacts using the Hamming window function at about 10 am, 2 $\mathrm{pm}, 12 \mathrm{pm}$, and $5 \mathrm{am}$. The fast Fourier transform analysis conditions included elimination of the DC component and use of the high-cut filter. Premature ventricular contractions were detected and interpolated to obtain a normalised RR interval. The power spectrum density was generated using multiple computation and the average fast Fourier transform of overlapping data segments. Maximum power spectral density from 0.04 to $0.15 \mathrm{~Hz}$ (low frequency power (LF)), from $0 \cdot 15$ to $0.40 \mathrm{~Hz}$ (high frequency power (HF)), and power in the band up to $0.40 \mathrm{~Hz}$ (total power) were calculated, as was the $\mathrm{LF}$ to $\mathrm{HF}$ ratio ( $\mathrm{LF} / \mathrm{HF}$ ratio). All normal values in our institution were collected from healthy 34 agematched subjects (unpublished data).

SIGNAL-AVERAGED ELECTROCARDIOGRAM

At an average of 30 days after surgery, the signal-averaged electrocardiogram (7T-18 model, Sanei, Tokyo, Japan) was recorded. After amplification (2500-fold) of chest bipolar leads $\mathrm{X}, \mathrm{Y}$, and $\mathrm{Z}$ and template waveform recognition using silver-silver chloride electrodes, bidirectional band processing was performed at $100-300 \mathrm{~Hz}$, and the R-wave synchronised signal-averaged electrocardiogram was recorded. A/D conversion was conducted at 12 bits and when the input signal was sampled, and the minimum resolution was $0.5 \mu \mathrm{V}$. The root mean square:

$$
\sqrt{\left(\mathrm{X}^{2}+\mathrm{Y}^{2}+\mathrm{Z}^{2}\right)}
$$

was calculated, and the filtered $\mathrm{P}$ duration for each patient was determined. The starting point of the $P$ wave was the point where the potential continued over $1 \mu \mathrm{V}$ of the recording with a noise level under $0.5 \mu \mathrm{V}$; the end point was the point of peak decrease from $1 \mu \mathrm{V}$ by vector magnitude. 
STATISTICAL ANALYSIS

Data are presented as mean (SD) or number (\%). Duration of atrial fibrillation is expressed as median (interquartile range). Student's $t$ test and Scheffé's F method were used to examine differences in baseline characteristics and indices of heart rate variability. Statistical significance was regarded as a $P$ value of less than 0.05 .

\section{Results}

BASELINE CHARACTERISTICS AND RESTORATION OF SINUS RHYTHM

There were four deaths in hospital and 100 long-term survivors. Sinus rhythm was restored in 73 of 100 cases. Restoration of sinus rhythm was more successful $(88.3 \%, 68$ of 77) in patients with a smaller left atrial diameter $(<65 \mathrm{~mm})$. Subjects were classified into three groups according to their findings at postoperative ambulatory electrocardiographic monitoring: patients in group $1(\mathrm{n}=73)(1 \mathrm{a}$ : 58 regular sinus rhythm; 1 b: 15 sinus rhythm with frequent premature atrial contractions $(<1000 /$ day)); patients in group $2(n=21)$ persistent atrial fibrillation; and patients in group $3(n=6)$ permanent pacemaker implantation because of sick sinus syndrome.

Preoperative baseline characteristics are shown in table 2 . Significant differences were noted in the cardiothoracic ratio $(59(8) \%$ in group $1 \mathrm{a}, 62(8) \%$ in group $1 \mathrm{~b}, 71(9) \%$ in group 2, and 69 (11)\% in group 3) and left atrial diameter $(53(10) \mathrm{mm}$ in group $1 \mathrm{a}, 58$ (13) $\mathrm{mm}$ in group $1 \mathrm{~b}, 69$ (15) $\mathrm{mm}$ in group 2 , and 66 (12) $\mathrm{mm}$ in group 3) measured by echocardiography. A significant difference was noted for previous cardiac surgery $3.4 \%$ in group $1 \mathrm{a}, 13.3 \%$ in group $1 \mathrm{~b}, 4.8 \%$ in group 2 , and $50.0 \%$ in group 3 ).

\section{NATURE OF ARRHYTHMIAS AND HEART RATE VARIABILITY}

Postoperative characteristics are shown in table 3. Premature atrial contractions were frequently noted (1920 (324)/day) in group $1 b$. Percentage circadian variation in heart rate in group 1a (34 (16)\%) and in group 1b (33 (18)\%) was lower than in the control group (44 (18)\%). In three patients (one in group la and two in group 1b), paroxysmal supraventricular tachycardia was recorded.

The time and frequency domain analysis of heart rate variability in group 1a, the control group, and the normal value in our institution are shown in tables 4 and 5 . In group 1a, all indices of heart rate variability, especially frequency domain analysis, tended to be lower than in the control group and healthy group. In the control group, total power, LF, and LF/HF ratio tended to be high in the daytime and low at night, and HF tended to be low in the daytime and high at night. On the other hand, in group 1a, diurnal variations in total power, $\mathrm{HF}, \mathrm{LF}$, and $\mathrm{LF} / \mathrm{HF}$ ratio were absent or reduced.

Table 2 Preoperative baseline characteristics of the patients: comparison of the three groups

\begin{tabular}{|c|c|c|c|c|}
\hline \multirow[b]{2}{*}{ Characteristic } & \multicolumn{2}{|l|}{ Group 1} & \multirow{2}{*}{$\begin{array}{l}\text { Group 2 } \\
(n=21)\end{array}$} & \multirow{2}{*}{$\begin{array}{l}\text { Group } 3 \\
(n=6)\end{array}$} \\
\hline & $1 a(n=58)$ & $1 b(n=15)$ & & \\
\hline $\begin{array}{l}\text { Age (y) } \\
\text { Sex (M/F) } \\
\text { Duration of AF (y) } \\
\text { Previous cardiac surgery (\%) } \\
\text { NYHA (class) } \\
\text { CTR (\%) } \\
\text { LAD (mm) } \\
\text { LVEF (\%) } \\
\text { Fundamental heart disease: }\end{array}$ & $\begin{array}{l}58 \cdot 4(9 \cdot 3) \\
24 / 34 \\
8 \cdot 8(5 \cdot 2-12 \cdot 0) \\
2(3 \cdot 4) \\
2 \cdot 6(0 \cdot 7) \\
59(8) \neq \dagger \\
53(10) \ddagger^{\star} \\
64(13)\end{array}$ & $\begin{array}{l}62 \cdot 1(9 \cdot 9) \\
7 / 8 \\
10 \cdot 2(6 \cdot 0-16 \cdot 2) \\
2(13 \cdot 3) \\
2 \cdot 7(0 \cdot 6) \\
62(8) \S \\
58(13) \star \star \\
60(9)\end{array}$ & $\begin{array}{l}61 \cdot 3(11 \cdot 1) \\
12 / 9 \\
11 \cdot 5(6 \cdot 2-18 \cdot 0) \\
1(4 \cdot 8) \dagger \\
2 \cdot 7(0 \cdot 9) \\
71(9) \\
69(15) \\
62(15)\end{array}$ & $\begin{array}{l}60 \cdot 2(12 \cdot 7) \\
2 / 4 \\
12 \cdot 4(6 \cdot 4-16 \cdot 0) \\
3(50 \cdot 0) \\
2 \cdot 3(0 \cdot 5) \\
69(11) \\
66(12) \\
63(9)\end{array}$ \\
\hline $\begin{array}{l}\text { Fundamental heart disease: } \\
\text { Mitral valve disease (\%) } \\
\text { MS } \\
\text { MR } \\
\text { MSR } \\
\text { Aortic valve disease (\%) } \\
\text { Congenital heart disease (\%) } \\
\text { Others (\%) }\end{array}$ & $\begin{array}{l}40(69 \cdot 0) \\
14 \\
18 \\
8 \\
7(12 \cdot 1) \\
6(10 \cdot 3) \\
5(8 \cdot 6)\end{array}$ & $\begin{array}{l}13(86 \cdot 7) \\
3 \\
7 \\
3 \\
2(13 \cdot 3) \\
0 \\
0\end{array}$ & $\begin{array}{l}19(90 \cdot 5) \\
5 \\
10 \\
4 \\
0 \\
2(9 \cdot 5) \\
0\end{array}$ & $\begin{array}{l}6(100 \cdot 0) \\
2 \\
2 \\
2 \\
0 \\
0 \\
0\end{array}$ \\
\hline
\end{tabular}

Data are presented as mean (SD) or median (interquartile range) or number (\%). AF, atrial fibrillation; NYHA, New York Heart Association function class; CTR, cardiothoracic ratio; LAD, left atrial diameter; LVEF, left ventricular ejection fraction; MS, mitral stenosis; MR, mitral regurgitation; MSR, mitral stenosis and regurgitation.

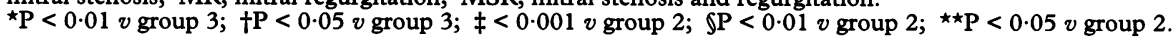

Table 3 Postoperative characteristics of the patients: comparison of the three groups

\begin{tabular}{|c|c|c|c|c|}
\hline \multirow[b]{2}{*}{ Characteristic } & \multicolumn{2}{|l|}{ Group 1} & \multirow{2}{*}{$\begin{array}{l}\text { Group } 2 \\
(n=21)\end{array}$} & \multirow{2}{*}{$\begin{array}{l}\text { Group } 3 \\
(n=6)\end{array}$} \\
\hline & $1 a(n=58)$ & $1 b(n=15)$ & & \\
\hline \multicolumn{5}{|l|}{ AECGM: } \\
\hline PAC (/24 h) & $220(41)^{\star}$ & $1920(324)$ & - & $198(90)^{\star}$ \\
\hline PVC (/24 h) & $104(245)$ & $330(615)$ & $487(738)$ & $43(35)$ \\
\hline$\%$ CVHR (\%) & $34(16)$ & $33(18)$ & $53(20)$ & $68(26)$ \\
\hline PSVT (\%) & $1(1 \cdot 7)$ & $2(13 \cdot 3)$ & - & - \\
\hline PAF (\%) & 0 & $6(40 \cdot 0)$ & - & - \\
\hline \multicolumn{5}{|l|}{ SAECG } \\
\hline FPD (ms) & $150(20)$ & $158(23)$ & - & - \\
\hline $\begin{array}{l}\text { Antiarrhythmic agent (\%): } \\
\text { Class Ia (\%) }\end{array}$ & $\begin{array}{l}5(8 \cdot 6) \dagger \\
2(3 \cdot 4) \dagger\end{array}$ & $\begin{array}{l}3(20 \cdot 0) \\
2(13 \cdot 3)\end{array}$ & $\begin{array}{l}7(33 \cdot 3) \\
4(19 \cdot 0)\end{array}$ & $\begin{array}{l}1(16 \cdot 7) \\
1(16 \cdot 7)\end{array}$ \\
\hline Class Ic (\%) & $3(5 \cdot 2)$ & $1(6 \cdot 7)$ & $3(14 \cdot 3)$ & 0 \\
\hline
\end{tabular}

Data are presented as mean (SD) or number (\%). AECGM, ambulatory electrocardiographic monitoring; PAC, premature atrial contraction; PVC, premature ventricular contraction; \%CVHR, \% circadian variation in heart rate; PSVT, paroxysmal supraventricular tachycardia; PAF, paroxysmal atrial fibrillation; SAECG, signal-averaged electrocardiogram; FPD, filtered P duration.

${ }_{\star}^{\star} \mathrm{P}<0.01 v$ group $1 \mathrm{~b} ;+\mathrm{P}<0.05 v$ group 2 . 
Table 4 Time domain analysis of heart rate variability in group 1a compared with controls*

\begin{tabular}{|c|c|c|c|c|}
\hline \multirow[b]{2}{*}{ Index } & \multicolumn{4}{|l|}{ Time } \\
\hline & 1000 & 1400 & 0000 & 0500 \\
\hline $\begin{array}{l}\text { Mean } R R(m s)(n=58): \\
\text { Control group }(n=20) \\
\text { Normal value } \\
\text { SD }(m s): \\
\text { Control group } \\
\text { Normal value } \\
\text { CV }(\%): \\
\text { Control group } \\
\text { Normal value }\end{array}$ & $\begin{array}{l}722(121) \\
754(103) \\
791(115) \\
20(11) \\
27(15) \\
32(19) \\
2.8(1.7) \\
3.8(1.9) \\
3.9(1.9)\end{array}$ & $\begin{array}{l}726(122) \\
755(103) \\
807(135) \\
21(11) \\
24(13) \\
29(19) \\
2 \cdot 7(1 \cdot 6) \\
3 \cdot 2(1 \cdot 6) \\
3.6(2 \cdot 1)\end{array}$ & $\begin{array}{l}760(103) \dagger \\
843(135) \\
957(144) \\
16(9) \\
19(8) \\
25(10) \\
2 \cdot 1(1 \cdot 2) \\
2 \cdot 3(1 \cdot 0) \\
2 \cdot 7(1 \cdot 0)\end{array}$ & $\begin{array}{l}766(116) \\
839(117) \\
957(204) \\
19(11) \\
23(6) \\
29(13) \\
2 \cdot 6(1 \cdot 7) \\
2 \cdot 7(0 \cdot 9) \\
3 \cdot 0(1 \cdot 1)\end{array}$ \\
\hline
\end{tabular}

Data are presented as mean (SD). Mean RR, mean of all coupling intervals between normal sinus beats; SD, standard deviation of successive RR intervals; CV, coefficient of variation. *Control group-patients with mitral valve disease who were in normal sinus rhythm preoperatively. Normal value, data collected from healthy 34 age-matched subjects in our institution. $+P<0.05 v$ control group.

Table 5 Frequency domain analysis of heart rate variability in group 1a compared with controls

\begin{tabular}{|c|c|c|c|c|}
\hline \multirow[b]{2}{*}{ Index } & \multicolumn{4}{|l|}{ Time } \\
\hline & 1000 & 1400 & 0000 & 0500 \\
\hline $\begin{array}{l}\text { Total power }\left(\mathrm{ms}^{2}\right)(n=58) \\
\text { Control group }(n=20) \\
\text { Normal value }\end{array}$ & $\begin{array}{c}323(336)^{\star} \\
793(966) \\
1052(1021)\end{array}$ & $\begin{array}{l}321(422) \\
630(684) \\
862(1241)\end{array}$ & $\begin{array}{l}215(278) \\
363(282) \\
718(566)\end{array}$ & $\begin{array}{l}286(486) \\
417(305) \\
930(875)\end{array}$ \\
\hline $\mathrm{HF}\left(\mathrm{ms}^{2}\right)$ & $96(136)$ & $75(105)$ & $70(101)^{\star}$ & 76 (137) \\
\hline Control group & $72(95)$ & $102(134)$ & $148(124)$ & $64(71)$ \\
\hline Normal value & $115(90)$ & $121(89)$ & $302(281)$ & $346(471)$ \\
\hline $\mathrm{LF}\left(\mathrm{ms}^{2}\right)$ & $39(79)$ & $15(25)^{\star}$ & $10(11) \neq$ & $24(96)$ \\
\hline Control group & $62(110)$ & $58(102)$ & $68(94)$ & $51(88)$ \\
\hline Normal value & $183(251)$ & $127(115)$ & $128(129)$ & $184(219)$ \\
\hline $\mathrm{LF} / \mathrm{HF}$ ratio & $0.4(0.2) \neq$ & $0.2(0 \cdot 2) \ddagger$ & $0.2(0.2) \dagger$ & $0.2(0 \cdot 2) \dagger$ \\
\hline Control group & $0.9(0.6)$ & $0.8(0.5)^{\top}$ & $0.4(0.3)$ & $0.4(0.4)$ \\
\hline Normal value & $1.4(1.0)$ & $1 \cdot 2(0 \cdot 7)$ & $0.5(0.4)$ & $0.6(0.4)$ \\
\hline
\end{tabular}

Data are presented as mean (SD). HF, high frequency; LF, low frequency. Control group, patients with mitral valve disease who were in normal sinus rhythm preoperatively. Normal patients with mitral valve disease who were in normal sinus rhythm preoper
value, data collected from healthy 34 age-matched subjects in our institution.

value, data collected from healthy 34 age-matched subjects in our institution.
$\star \mathrm{P}<0.05 v$ control group; $+\mathrm{P}<0.01 v$ control group; $¥ \mathrm{P}<0.001 v$ control group.

\section{FILTERED-P DURATION}

A signal-averaged electrocardiogram was obtained in 73 patients in group 1 a or group 1b. The filtered $P$ durations in group 1a (150 (20) $\mathrm{ms}$ ) and group $\mathrm{lb}$ (158 (23) $\mathrm{ms}$ ) were longer $(P<0.01)$ than in control group $(122$ (11) $\mathrm{ms}$ ).

\section{MEDICATION}

No attempt was made to standardise treatment. Medications after the maze procedure in each group are shown in table 3 . The proportion of patients who were treated with antiarrhythmic agents was significantly lower $(P<0.05)$ in group 1a than in group 2.

\section{Discussion}

We found restoration of sinus rhythm in $73.0 \%$ of all patients, and in $88.3 \%$ of patients with a left atrial diameter $<65 \mathrm{~mm}$. Heart rate variability was less in patients in whom sinus rhythm was restored than in the control group that underwent heart surgery. The signal-averaged $P$ wave was longer in patients in whom sinus rhythm was restored than in the control group that underwent heart surgery.

\section{PATIENTS}

Cox et al reported a high rate of restoration of sinus rhythm with the maze procedure. ${ }^{14}$ However, half of their patients had paroxysmal atrial fibrillation and three quarters had idiopathic lone atrial fibrillation. Currently, in Japan the maze procedure is not used in patients with lone atrial fibrillation. Therefore, in our institution, we used the Cox maze procedure in patients with organic heart diseases.

\section{POSTOPERATIVE ARRHYTHMIAS AFTER THE} MAZE PROCEDURE

In the present study, we found that the left atrial diameter was slightly larger in patients with frequent premature atrial contractions $(<1000 /$ day) than in group 1a. This finding does not rule out the possibility that the frequent premature atrial contractions were caused by degeneration of the atrium. Cox et al reported, however, that paroxysmal atrial fibrillation sometimes occurred immediately after the maze procedure; factors responsible for such fibrillation include oedema, pericarditis, surgical trauma, and catecholamines. ${ }^{14}$ Most authors believe that the atrium has not yet recovered from the surgical procedure itself and that most patients develop atrial arrhythmias early after surgery. Our present study is based on early electrocardiographical results. At one year follow up we found the same incidence of restored sinus rhythm in the two groups of diameters, and a decrease in premature atrial contractions (unpublished data).

CIRCADIAN CHANGES OF HEART RATE

VARIATION AFTER THE MAZE PROCEDURE

A fast Fourier transform analysis of changes in the $R R$ interval recorded by ambulatory electrocardiographic monitoring evaluates autonomic nerve function. In a fast Fourier transform analysis of changes in the RR interval in healthy individuals, diurnal variations were observed, with the LF power tending to be high in the daytime and low at night, and the $\mathrm{HF}$ power tending to be low in the daytime and high at night. Furthermore, Bigger et al reported that the range of power values and diurnal variations tended to decrease with a age. ${ }^{15}$ Therefore, age and the timing of measurements are critical in the evaluation of $\mathrm{HF}$, $\mathrm{LF}$, and $\mathrm{LF} / \mathrm{HF}$ ratio. This is why we show age-matched normal values in tables 4 and 5 (unpublished data). After the maze procedure diurnal variations in total power, $\mathrm{HF}, \mathrm{LF}$, and $\mathrm{LF} / \mathrm{HF}$ ratio were significantly decreased in patients in group 1a. Circadian variations in autonomic nerve activity were significantly reduced after the maze procedure. Possible mechanisms include denervation after the maze procedure or suppression of sinus node function after degeneration of sinus node cells, but the aetiology remains unknown. Ueshima et al reported that the heart rate response to exercise soon after successful cardioversion to normal sinus rhythm was consistent with chronotropic incompetence. ${ }^{16}$ Tamai et al reported that the mean heart rate and oxygen uptake at peak exercise were reduced soon after the maze procedure. ${ }^{17}$ Both reports showed that the response of the sinoatrial node to exercise was reduced early after the maze procedure; however, exercise capacity was improved late after the maze procedure. One year after the maze procedure indices of heart rate variability were improved (unpublished data). 
ATRIAL CONDUCTION AND ARRHYTHMOGENESIS AFTER THE MAZE PROCEDURE

Guidera and Steinberg reported that filtered P duration was significantly longer in paroxysmal atrial fibrillation than in normal individuals, and also that filtered $P$ duration in the signal-averaged electrocardiogram during sinus rhythm was useful as a non-invasive index for predicting paroxysmal atrial fibrillation. ${ }^{18}$ The maze procedure requires sutures in the atrium because of the complexity of the atrial incision. It was suggested that the maze procedure produces non-uniform transmission around the suture lines in the atrium, and this could cause reentrant atrial tachyarrhythmia. When the $P$ wave, which recovers after the maze procedure, was analysed by signal-averaged electrocardiography, filtered $\mathrm{P}$ duration potential was significantly greater than in the control group, and this change was much more marked in patients with atrial arrhythmias after surgery. It is likely that tissue near the suture lines causes uneven conduction of impulses, and this is related to the onset of atrial tachycardia after surgery. In this study, paroxysmal supraventricular tachycardias were newly recorded in three patients after the maze procedure. Chiba et al reported that intraatrial reentrant tachycardias were diagnosed by electrophysiological study a mean of three weeks after surgery. ${ }^{19}$ Intra-atrial reentrant tachycardias were reproducibly induced and terminated by a single right atrial extrastimulus on electrophysiological study. The cycle lengths of intra-atrial reentrant tachycardias ranged from 220 to $550 \mathrm{~ms}$ (mean $422 \mathrm{~ms}$ ). We believe that the incisions and suture lines cause anatomical slow conduction zones and subsequent intra-atrial reentrant tachycardias. Post-surgical atrial tachycardias tended to be less common after cryoablative surgery to the interatrial septum, coronary sinus, and tricuspid annulus.

\section{PREDICTORS OF SUCCESS}

Age, gender, and duration of atrial fibrillation did not predict restoration of sinus rhythm. However, restoration of sinus rhythm was more common $(88.3 \%)$ in those with a smaller left atrial diameter $(<65 \mathrm{~mm})$. Kosakai et al have already pointed out that patients who remain in atrial fibrillation have a larger left atrial diameter preoperatively. ${ }^{9}$ Furthermore, Segawa et al reported that the atrium showed severe degeneration and fibrosis in patients who had persistent atrial fibrillation after the concomitant maze procedure. ${ }^{20}$ On the other hand, we reported that the intraoperative atrial epicardial mapping data were useful for predicting the restoration of sinus rhythm. ${ }^{21}$ Preoperative average peak to peak atrial amplitude during atrial fibrillation was significantly higher in patients in whom sinus rhythm was restored than in patients with persistent postoperative atrial fibrillation. These findings suggest that restoration of sinus rhythm cannot be expected in cases where the atrium is expanded to the point of degeneration and fibrosis. If the patients had sick sinus syndrome preoperatively, one would not expect the maze procedure to restore the sinus node function despite abolition of the atrial fibrillation. Preoperative evaluation of the sinus node function and atrioventricular conduction may be helpful in preventing postoperative sick sinus syndrome. Unfortunately, an electrophysiological study was not performed preoperatively in this study. Interestingly, three of these six patients had had previous surgery. However, we had no definite data to indicate that multiple surgical procedures caused the damage to the sinus node: the aetiology was unknown.

INDICATION OF THE MAZE PROCEDURE

The maze procedure may avoid the detrimental consequences associated with atrial fibrillation. In Japan the number of patients with rheumatic heart disease has decreased, but the percentage of cases of valvar heart disease with atrial fibrillation is still high. Furthermore, the number of patients with mitral valve disease who need valve repair and the maze procedure has increased recently. The maze procedure, because it does not require any postoperative anticoagulant therapy, may be particularly useful in such cases. Further follow up study of the incidence of thrombotic events and the evaluation of quality of life are needed to assess the Cox maze procedure. A randomised controlled trial is needed to determine the advantages and disadvantages of the maze procedure.

\section{CONCLUSIONS}

Restoration of sinus rhythm was more likely to be successful in patients with smaller left atrial diameters. However, the maze procedure may result in a decreased sinus response and nonuniform transmission of impulses in the atrium.

Part of this paper was presented at the Seventeenth Congress of The European Society of Cardiology, 20-24 August 1995 , Amsterdam, The Netherlands.

1 Cox JL, Schuessler RB, Boineau JP. The surgical treatmen of atrial fibrillation. I. Summary of the current concepts of the mechanisms of atrial flutter and atrial fibrillation. $\mathscr{f}$ Thorac Cardiovasc Surg 1991;101:402-5.

2 Cox JL, Canavan TE, Schuessler RB, Cain ME, Lindsay $\mathrm{BD}$, Stone C, et al. The surgical treatment of atrial fibrillation. II. Intraoperative electrophysiologic mapping and description of the electrophysiologic basis of atrial flutter and atrial fibrillation. $₹$ Thorac Cardiovasc Surg 1991;101: and atrial 26.

3 Cox JL, Schuessler RB, D'Agostino HJ, Stone CM, Chang B-C, Cain ME, et al. The surgical treatment of atrial fibrillation III. Development of a definitive surgical procerillation III. Development of a definitive surgical
dure. $\mathcal{F}$ Thorac Cardiovasc Surg 1991;101:569-83.

4 Cox JL. The surgical treatment of atrial fibrillation. IV. Surgical technique. $\mathcal{F}$ Thorac Cardiovasc Surg 1991;101 584-92.

5 Cox JL, Boineau JP, Schuessler RB, Ferguson TB, Cain ME, Lindsay BD, et al. Successful surgical treatment of atrial fibrillation. Review and clinical update. $\mathfrak{F} A M A$ 1991;266:1976-80.

6 Konings KT, Kirchhof CJ, Smeets JR, Wellens HJJ, Penn OC, Allessie MA. High-density mapping of electrically induced atrial fibrillation in humans. Circulation 1994; 89:1665-80.

7 Bonchek LI, Burlingame MW, Worley SI, Vazales BE Lundy EF. Cox/maze procedure for atrial septal defect with atrial fibrillation: management strategies. Ann with atrial fibrillation: mana

8 McCarthy PM Cosgrove DM III, Castle LW, White RD, Klein AL. Combined treatment of mitral regurgitation and atrial fibrilation with valvuloplasty and the maze proand atrial fibrilation with valvuloplasty
cedure. $A m \mathcal{F}$ Cardiol 1993;71:483-16.

9 Kosakai Y, Kawaguchi AT, Isobe F, Sasako Y, Nakano K, Eishi $\mathrm{K}$, et al. Cox maze procedure for chronic atrial fibrillation associated with mitral valve disease. $\mathcal{f}$ Thorac Cardiovasc Surg 1994;108:1049-55. 
10 Kosakai Y, Kawaguchi AT, Isobe F, Sasako Y, Nakano K, Eishi $\mathrm{K}$, et al. Modified maze procedure for patients with atrial fibrillation undergoing simultaneous open heart surgery. Circulation 1995;92(suppl II): III359-64.

11 Kobayashi J, Kosakai Y, Kawashima Y. Maze procedure and anomalous coronary artery repair. Ann Thorac Surg 1996;61:1008-11.

12 Sato S, Kawashima Y, Hirose H, Nakano S, Matsuda H, Shirakawa $R$. Long-term results of direct-current cardioversion after open commissurotomy for mitral stenodioversion after open commissuro
sis. Am $\mathcal{F}$ Cardiol 1986;57:629-33.

$13 \mathrm{Cox} \mathrm{J}$. Evolving applications of the maze procedure for atrial fibrillation. Ann Thorac Surg 1993;55:578-80.

14 Cox JL, Boineau JP, Schuessler RB, Kater KM, Lappas DG. Surgical interruption of atrial reentry as a cure for atrial fibrillation. In: Olsson SB, Allessie MA, Campbell RWF, eds. Atrial fibrillation: mechanisms and therapeutic strategies. Armonk, NY: Futura, 1994; 374-404.

15 Bigger JT Jr, Fleiss JL, Steinmann RC, Rolnitzky LM, Schneider WJ, Stein PK. RR variability in healthy, middle-aged persons compared with patients with chronic coronary heart disease or recent acute myocardial infarccoronary heart disease or recent acut

16 Ueshima K, Myers J, Morris CK, Atwood JE, Kawaguchi
T, Froelicher VF. The effect of cardioversion on exercise capacity in patients with atrial fibrillation. Am Heart $\mathcal{f}$ 1993;126:1021-4.

17 Tamai J, Kosakai Y, Yoshioka T, Ohnishi E, Takaki H, Okano Y, et al. Delayed improvement in exercise capacity with restoration of sinoatrial node response in patients after combined treatment with surgical repair for organic heart disease and the maze procedure for atrial fibrillation. Circulation 1995;91:2392-9.

18 Guidera SA, Steinberg JS. The signal-averaged $P$ wave duration: a rapid and noninvasive marker of risk of atrial duration: a rapid and noninvasive marker of risk

19 Chiba N, Ito M, Kubota M, Hosokawa S, Onodera S, Yagi $\mathrm{Y}$, et al. Maze procedure creates anatomical slow conduction zone as developing reentrant atrial tachycardia (abstract). Circulation 1994;90:I595.

20 Segawa I, Tashiro A, Sato M, Hiramori K, Yagi Y, Kawazoe K. Clinical experience of the tissue characterization of the atrium and clinical course after the maze procedure (abstract). Fpn Circ f 1995;59:179.

21 Yagi $Y$, Mukaida $M$, Chiba $N$, Kamata J, Izumoto $H$, Sasaki T, et al. Predictors of clinical outcome of maze (Cox III) procedure for chronic atrial fibrillation associated with underlying heart disease: the importance of atrial epicardial mapping (abstract). Circulation 1995; 92:I84-5. 